\title{
REPLICATION AND FUNCTIONS OF MACRONUCLEAR DNA IN SYNCHRONOUSLY GROWING POPULATIONS OF TETRAHYMENA PYRIFORMIS
}

\author{
H. A. ANDERSEN \\ Biological Institute of the Carlsberg Foundation, \\ Tagensvej 16, 2200 Copenhagen N., Denmark
}

Key words: DNA replication, Tetrahymena

It is the objective of this article to discuss aspects of the macronuclear DNA replication and function in heat synchronized populations of Tetrahymena pyriformis. The thymidine analogue 5-bromodeoxyuridine was used as a density marker of synthesized DNA. This density label of DNA, followed by gradient centrifugation, was used to measure DNA replication quantitatively and to gain information about the nature of the DNA synthesis, which takes place at various periods of the cell cycle. Some of the events in the synchronized cell cycle, which are described, may be summarized briefly: After a synchronous cell division the cells initiate a synchronous replication of the macronuclear DNA. The DNA replication begins with replication of the ribosomal genes. Thereafter the bulk nuclear DNA replicates, and parallel with this the genes coding for $5 S$ rRNA and tRNA. The replication of bulk DNA may follow a fixed sequence in each S-period, ensuring full replication of all DNA without double replication of any DNA fraction. However, the replication sequence changes from generation to generation, possibly due to a mixing of the nuclear subnuclei prior to division. The cells appear to have a full complement of genes replicated before the end of the macronuclear S-period. Obligatory DNA synthesis ends and G2-activities are initiated when $70-80 \%$ of the DNA has been replicated. The cells are able to divide after the DNA replication has been inhibited in the latter half the preceding S-period. Such cells divide with a fraction of their DNA only partially replicated. This DNA fraction is eliminated from the macronucleus at the time of the division, and it is localized in the cytoplasm during the next cell generation. When the inhibitory treatment is removed at the time of cell division, the extruded DNA continues its replication after the end of the macronuclear S-period. Furthermore, it was found that thymidine starvation, here used as a specific inhibitor of DNA replication, tended to stop replication preferentially in regions of the molecules with relative high $\mathrm{dAdT}$ base content and leaving molecules with single stranded regions.

Bromodeoxyuridine, which has been a valuable tool in the analysis of the DNA replication in Tetrahymena, is under special circumstances a potent inhibitor of macromolecular synthesis and cell proliferation. Bromodeoxyuridine has to be incorporated into DNA in high amounts before any inhibitory effects are seen. As soon as DNA contains bromodeoxyuridine in sufficient amounts, it will affect transcription, but the various genes respond differently to the substitution. The rDNA, i.e. the genes coding for the two large ribosomal RNA molecules (17S- and 25S RNA) were found to be most sensitive. 


\section{CONTENTS}

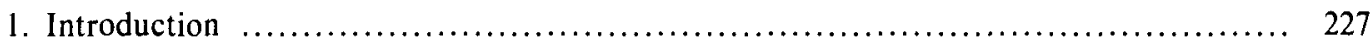

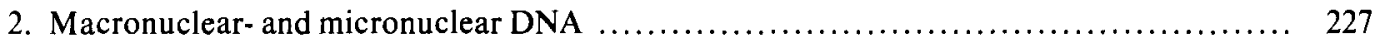

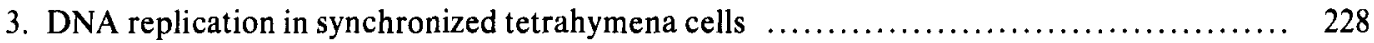

3.1 DNA synthesis in cultures exposed to seven heat shocks prior to division ............. 229

3.2 DNA synthesis in cultures exposed to one heat shock per cell generation .............. 230

3.2.1 Change of DNA replication sequence from generation to generation ............ 230

3.2 .2 Replication of specific genes ..................................... 231

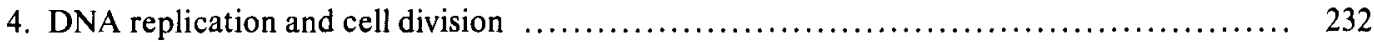

5. Elimination of nuclear DNA

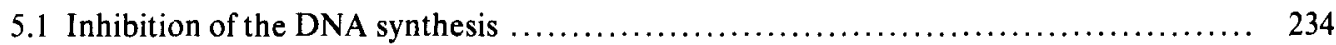

5.2 Elimination of macronuclear DNA in Tetrahymena .......................... 234

5.2.1. Extrusion bodies in Tetrahymena ...................................... 235

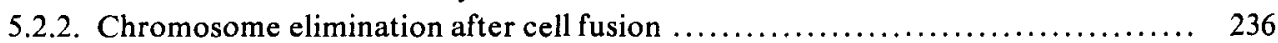

5.2.3. Cytoplasmic DNA in other cell types ............................... 236

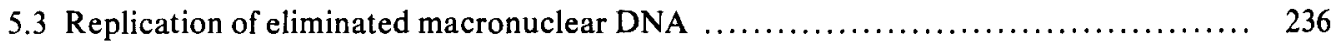

5.3.1. Replication and transcription of mammalian genes not located on chromosomes 238

5.3.2. Replication of injected DNA in oocyte and egg cytoplasm ................ 238

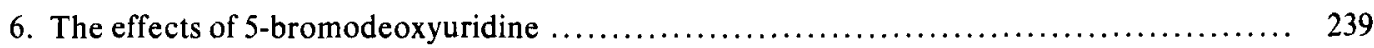

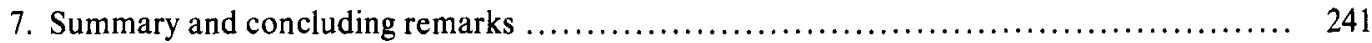

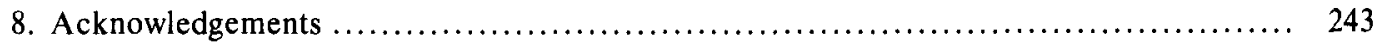

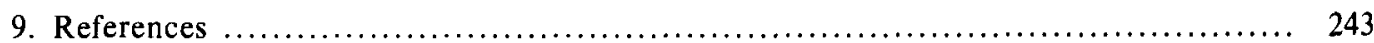




\section{INTRODUCTION}

Synchronously growing populations of Tetrahymena pyriformis offer unique material for studies of events in an animal cell cycle. No other animal cell population can be synchronized with the same high degree of reproducibility from generation to generation as populations of Tetrahymena treated with one so called heat shock per cell cycle, as described by ZEUTHEN in 1971 (120). The synchronized cell cycle may differ in various ways from the cell cycle in cells grown exponentially. However, these differences may be considered as variations of "normal" cell cycles seen in nature, when cells are confronted with variations in their surroundings: media, temperature etc., variations to which any Tretrahymena cell in nature must be able to adjust.

The synchronized cell cycle, as any other cell cycle, can be characterized by a series of interlinked biochemical events, controlled relative to each other and controlling each other which ensure both doubling of cell parameters before the cell divides, and proper timing of the events which lead to division. Synchronization of the cells opened the way to biochemical studies of the cell cycle. The mechanisms in the induction of division synchrony, and the Tetrahymena cell cycle, have been studied for more than twenty years (for recent reviews, see references: $11,116,121,122$, 124).

The present work is part of the research program at the Biological Institute of the Carlsberg Foundation, which has been centered on the synchronization of Tetrahymena. The purpose of the present article is 1) to describe the DNA replication in synchronized populations of Tetrahymena pyriformis, 2) to elucidate the organization and function of the macronuclear DNA, and 3) to study phenomeria of general biologial significance for which the Tetrahymena system is especially suitable, such as the extrusion of macronuclear DNA, the replication of such extruded DNA in the cytoplasm, and the biological effects of incorporation of 5bromodeoxyuridine into DNA.

\section{MACRONUCLEAR-AND MICRO- NUCLEAR DNA}

Tetrahymena belongs to the group of holotrich ciliates. These cells have typically two kinds of nuclei, micro- and macronuclei. The micronucleus takes part in sexual reproduction, divides by mitosis or meiosis, and gives rise to a macronucleus after conjugation. The $2 n$ number of chromosomes equals 10 . As far as we know micronuclear DNA is never transcribed, exept perhaps for purposes of its own reproduction (48,82). A macronucleus in Tetrahymena pyriformis contains on average 23 times as much DNA as a micronucleus in the $2 \mathrm{n}$ state (113). This DNA is organized in about 45 "subnuclei" or clumps of chromatin granules, visible at the time of division $(86,87)$. Some strains of Tetrahymena pyriformis are amicronucleate and multiply exclusively vegetatively. Here the function of the macronucleus is basically the same as that of a somatic nucleus in the metazoan body. It has two general functions: 1) it is the seat and the instrument for the reproduction of the genetic apparatus in each cell generation, and 2) it is the site from which genetic information is released to the cell.

As mentioned above, macronuclear DNA is organized in clumps of chromatin, and no chromosomes can be identified. The total amount of DNA has been estimated to be $4-6 \times 10^{12}$ daltons $(44,47,113)$ and various studies have indicated that this DNA contains most if not all of the genetic information found in the micronuclear genome. Contrary to the selective amplification of DNA during the formation of macronuclei in hypotrich ciliates $(4,92)$, the macronucleus of Tetrahymena appears genetically as a multiple version of the micronucleus. From kinetic complexity studies ALLEN and GiBSON (1), concluded that the macronuclear and micronuclear genome size were the same, and YAO and GoROvSKY (114) found that 80-90 percent of the mocronuclear DNA would hybridize to macronuclear DNA. However, macro- and micronuclei differ in their amounts of ribosomal genes. The number of genes coding for $17 \mathrm{~S}$ and $25 \mathrm{~S}$ ribosomal RNA is amplified in the macronucleus, and the relative amplification per genome is around 200 
fold $(38,115)$. These genes are localized in the numerous (500-1000) nucleoli which are positioned in close contact with the macronuclear membrane. Nucleoli are not present in the micronucleus. The nucleolar DNA rDNA- consists of separate, linear molecules with molecular weight of $12.6 \times 10^{6}$ daltons, and each molecule contains two genes for $17 \mathrm{~S}$ and $25 \mathrm{~S}$ ribosomal RNA. Recent experiments in which these molecules have been digested with restriction endonuclease have shown that the rDNA molecules are giant palindromes (41, $42,46,65)$. This DNA fraction is autonomous with respect to timing of its replication (see section 3.2.2.).

Various hypotheses have been proposed for the organization of macronuclear DNA. Based on genetic observations, NANNEY (84) and ALLEN and NANNEY (3) assumed that the genetic material of the macronucleus is composed of around 45 diploid subnuclei. However, the relative DNA measurements mentioned above set an upper limit of 23 on the number of diploid subnuclei in the macronucleus, each having the DNA content of a diploid micronucleus. If the 45 structural subnuclei described by NiLsSON $(86,87)$ are equivalent to micronuclear genomes these have to be haploid as stated by NILSSON, or fragments of the diploid micronuclear genome (nucleosomes) as proposed by VOROBEV et al. (111). In a genetic study ORIAS and FLACKS (89) followed the segregation of macronuclear gene copies, and concluded that 45 copies, randomly distributed, represents the actual number of gene copies. This conclusion, coupled with the estimations of macronuclear DNA content, suggests that the segregating units in the macronucleus are haploid.

An alternative hypothesis was proposed by ALLEN and GIBSON $(1,2)$ according to which the macronucleus contains only one replicative diploid genome (the "master") and a number of free non-replicative copies of its genes ("slaves"). The masters are replicated and distributed exactly between the two daughter nuclei at macronuclear division, while the slaves are distributed randomly. New slaves are assumed to be produced to compensate for halving their number at macronuclear division.
This hypothesis was proposed to explain such genetic phenomena as phenotypic assortment and determination of the Tetrahymena strains after conjugation, but it is not compatible with available experimental data to be described in the following sections of this paper.

In the author's view most data support the hypothesis that the macronucleus contains about 45 copies of the haploid micronuclear genome. At each nuclear division these genomes are distributed randomly and rather unprecisely between the two daughter cells (33). This contributes to a great variation in DNA content of different cells in a population. However, regulatory mechanisms keep the amount of DNA per nucleus within certain limits. Thus CLEFFMANN (29) found that when the amount of DNA in a nucleus decreased below a threshold value, an excess replication round was initiated before the end of the first round, and thus the amount of DNA was quadrupled within that particular cell cycle. The duration of this cell cycle was only slightly extended over the normal. The cells can also acquire excess amounts of DNA and put regulatory mechanisms in action to re-establish lower amounts of DNA per cell. Cells treated with a series of heat shocks, which inhibit cell divisions but permit extra rounds of DNA replication accumulate DNA. The DNA content of such cells can return to normal after two cell divisions without interjacent DNA replication (see section 3.1.).

\section{DNA REPLICATION IN SYNCHRONIZED TETRAHYMENA CELLS}

The following gives a short description and discussion of the author's findings. The cells, Tetrahymena pyriformis, amicronucleate strain GL, were synchronized by two different heat shock procedures, described by SCHERBAUM and ZeUTHeN (100,123) and Zeuthen (121). These techniques have been thoroughly described and discussed in recent reviews (11, $116,118,121,122,124)$, and in the present paper they will only be discussed in relation to the macronuclear DNA replication. 


\subsection{DNA Synthesis in Cultures Exposed to Seven Heat Shocks Prior to Division}

During this heat shock treatment $(100,123)$ cell divisions are blocked, but synthesis of protein, RNA and DNA continues in asynchrony at about half the previous rate. The amount of DNA per average cell has been determined chemically by SCHERBAUM (98) and by ZEUTHEN and RASMUSSEN (124), and the replication has been followed by use of 5bromodeoxyuridine (BUdR) as a density label for new DNA (8). These two approaches have yielded similar results. The question whether DNA synthesis proceeds linearly or shows small periodicities in the population during the treatment as stated by HoLM (56) is not settled. Small variations in the rate of DNA synthesis cannot be excluded on the basis of experiments with BUdR, but no dramatic change in the rate of DNA synthesis can be measured until about 40 minutes after the end of the heat treatment (fig. 1), although nuclear morphology has been shown to change during the heat treatment (88).

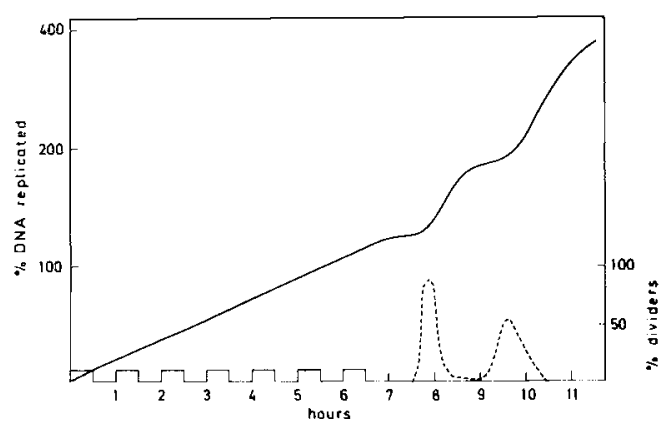

Figure 1. DNA replication in Tetrahymena pyriformis during and after the synchronizing heat treatment. The dotted line shows the first and the second division maxima. (From ANDERSEN et al. (8)).

The BUdR experiments show that the cells go through an average of 1.2 replication rounds during the seven heat shocks and this corresponds to an average increase in DNA of 140 percent per cell (fig. 1). During the heat treatment the fraction of cells in DNA synthesis at any time is lower than in normally growing cells. HJELM and ZEUTHEN (53) suggested that the heat treatment causes extension of the in- terval between the S-periods, whereas the duration of the S-period in the single cell is about normal. This suggestion has been confirmed by JEFFERY (61) and JEFFREY et al. $(62,63)$ in an autoradiographic study on single cells, and by ClefFMAN (30) and it agrees well with the results from the experiments with BUdR (8). We may conclude that the heat shocks have little effect on the DNA replication, but they do inhibit other division-relevant processes. About 40 minutes after the end of the last heat shock these processes accelerate, and morphological changes which normally precede cell division can be seen (45), and no more cells initiate DNA synthesis. In other words, about 40 minutes after the end of the last heat shock nearly all cells in the population enter prophase (defined by NiLSSON as the period with visible chromatin condensation $(86,87)$ ) and this represses initiation of the macronuclear DNA replication, ensuring that no cells divide when the nucleus is in the $S$ phase.

The first synchronous division occurs around 95 minutes after the end of the final heat shock, and the DNA synthesis is resumed immediately after this division in 50-70 percent of the cells $(53,54)$. In the experiment described by ANDERSEN et al. (8), we found that 50 percent of the DNA in the population replicated within an hour after the division. This shows that about half of the cells initiate DNA replication in good synchrony after the division and that they then double their DNA content. The second synchronous division takes place over a greater time interval than the first, partly because those cells which did not replicate between the first and the second synchronous division divide earlier than the rest of the cells. The BUdR experiments show that no cells initiate a second DNA replication round before all the cells have been in DNA replication once. In other words, none of the cells which incorporate BUdR into DNA between the two synchronous divisions replicate this labelled DNA again until the rest of the cells have incorporated BUdR into DNA in the replication round taking place after the second division. By inhibition of the DNA synthesis between the two divisions, ZEUTHEN (119) measured the timing of the residual second syn- 
chronous cell division, and found that a cell cycle without DNA replication was shortened by about 30 minutes.

While the vast majority of the cells goes through two synchronized divisions, only about half of the cells replicate their DNA between the two divisions; this shows a loose coupling between DNA replication and cell division. This deserves a comment: during heat treatment the cells replicate DNA asynchronously and after about 5.5 hours all cells contain an amount of DNA corresponding to at least the G2 level. Consequently, with respect to DNA content, all the cells are now ready to divide at constant optimum temperature. However, the treatment continues for another 1.5 hours, and the cells continue to engage in DNA synthesis at the rate of about 20 percent per hour (119). In accordance with this time schedule about 30 percent of the cells have had time to finish a second DNA replication round prior to the first synchronous cell division, and this excess replication round, or the DNA which results from it, is related functionally to the second synchronous division. In other words, some cells synthesize DNA in advance and acquire capacity to go from one cell division to the next without an S-period.

\subsection{DNA Synthesis in Populations Exposed to One Heat Shock Per Cell Generation}

Remarkable progress in synchronization of Tetrahymena was obtained when ZEUTHEN (120) introduced one heat shock per cell generation as a synchronization treatment. It then became possible to cultivate a cell population which would grow and divide in synchrony generation after generation, and, in principle, indefinitely. It can be assumed that such repeated synchrony is obtained only if other parameters in the cell cycle are synchronized equally well as the cell division. With respect to the DNA replication our studies have shown this to be the case. Autoradiography of cells, pulse-labelled with radioactive thymidine, indicated that most of the cells were in DNA synthesis after each cell division (120). Further studies on this DNA synthesis, using BUdR incorporation as a marker for newly replicated DNA demonstrated the DNA synthesis to be normal semiconservative replication, beginning immediately after the cell division. The DNA synthesis was found to be synchronized to the same high degree as the preceding division (9). The experiments revealed that all DNA in the population attained "hybrid density" during a period of 80-90 minutes after the division. This time corresponds to the duration of the $S$ period in a single log-phase cell of about 60 minutes $(25,110)$ plus the time within which the population divides (see figure 2).

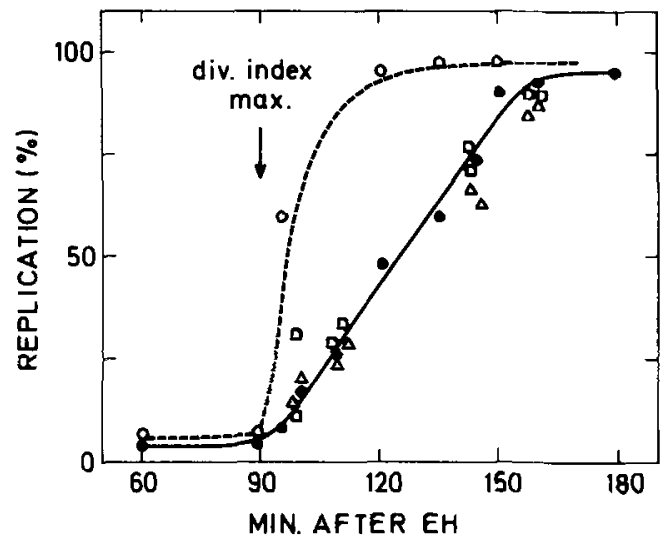

Figure 2. DNA replication in Tetrahymena pyriformis after synchronization by one heat shock per cell generation. The curves shows the percentage of bulk DNA (๑), rDNA (O) and DNA coding for 5Sand t-RNA $(\square, \triangle)$, replicated after a synchronizing heat shock. (Based on data from ANDERSEN and ENGBERG (10) and TøNNESEN and ANDERSEN (109)).

\subsubsection{Change of DNA replication sequence from generation to generation}

In each synchronized S-period macronuclear DNA is replicated fully, and no double replication has been found to take place $(6,9)$. This means that some kind of regulatory mechanism in the single cell ensures that all nuclear DNA replicates before any measurable fraction of the DNA initiates new replication. However, the replication programme is not the same in two consecutive replication rounds. The fraction of DNA in the population - and in the single cell which replicates late in one S-period is replicated again throughout the following $S$ period (9). Similarly, the DNA fraction which 
replicates early in one S-period is replicated next time throughout the whole following Speriod. In contrast, a fixed replication sequence of nuclear DNA has been described for many other cell types $(19,20,81,104,91)$. It has been found that such a fixed replication sequence mirrors differences in the base composition of the DNA which replicates at different times in the nuclear S-period $(15,16,17,43,105)$. Differences in the base composition between DNA replicating early or late in the S-period of Tetrahymena could not be detected: pulse labelling of DNA at different times in the Speriod revealed no difference in buoyant density of DNA labelled early or late, and they were not different from the buoyant density of the bulk of nuclear DNA $(6,12)$

The change in replication sequence observed is probably a reflection of the special organization of the macronuclear DNA in about 45 independent units the size of haploid genomes. It is suggested that these units become mixed at the time of the nuclear division, by analogy to the mixing of the macronuclear DNA seen in the two hypotrich ciliates, Euplotes and Stylonychia $(67,4)$. AMMERMANN has studied the formation of the macronucleus in Stylonychia after conjugation. He found that the high ploidy of this nucleus resulted from repeated replication rounds without interjacent nuclear divisions. The early rounds gave rise to polytene chromosomes, which later disintegrated and the bands became isolated granules. Then followed a series of replication rounds of a fraction of the macronuclear DNA (the second polyploidization stage). This replication takes place in bands which start at the two ends of the long macronucleus and travels to its middle, as in Euplotes. The replication bands can be labelled in a short pulse with tritiated thymidine, so that the location of the pulse labelled DNA can be followed through the S-period. AMMERMANN observed that the location of new DNA was fixed through the replication rounds responsible for amplification of the macronuclear DNA. However, just prior to the nuclear division the pulse labelled DNA became evenly distributed over the nucleus, and it stayed evenly distributed throughout the two daughter nuclei.
Replication bands have not been seen in the macronucleus in Tetrahymena. This does not exclude, however, that the replication of DNA follows a spatial program. The round macronucleus in Tetrahymena may impede the observation of such a program.

\subsubsection{The replication of specific genes}

The general statement that macronuclear DNA is mixed prior to each macronuclear division, and that this fixes a new DNA replication sequence in the next S-period, must be qualified with respect to the group of autonomous ribosomal RNA genes. This minor DNA fraction constitutes about 0.5 percent of the macronuclear DNA, and can not be distinguished in the type of experiments described. However, the replication of genes for which the transcript can be isolated, has been followed by a combination of the BUdR labelling of total DNA and hybridization of DNA with the radioactively labelled transcript. Few transcripts are presently available from eukaryote cells, and in Tetrahymena only those from the highly repetitive genes coding for ribosomal RNA (17S- and 25S RNA), 5S-RNA and $t$-RNA. Thus, using the DNA/RNA hybridization technique it was found that replication of the ribosomal genes took place in a short period of time at the beginning of the macronuclear S-period (10), whereas the replication of the 5S-RNA and t-RNA genes occurred in parallel with the bulk of nuclear DNA, see figure 2 (109). Such differences in the replication program between these genes probably reflects their different localization in the nucleus. Whereas the ribosomal genes are positioned in the separate nucleolar DNA as described in section 2, the 5S-RNA and the tRNA genes are located in the bulk DNA (68, $107,108)$. The high number of 5S-RNA and tRNA cistrons might suggest a scattered distribution of these genes within the single genome, reminiscent of the situation in Xenopus where the 5S-RNA and t-RNA genes are represented in most, if not all chromosomes $(28,90)$.

Thus, the macronuclear S-period in Tetrahymena begins with replication of nucleolar DNA. Since the S-period is initiated 
immediately after the nuclear division in heat synchronized cells, the GI-period is absent, and experiments with these cells supply no information corcerning the timing of $\mathrm{rDNA}$ replication in cells grown under conditions when a G1. period separates cell division and DNA replication. In other words, whether rDNA replication is coupled to a phase in the G1-period e.g. either the cell division or the initiation of the $S$ period, has not been settled. However, other experiments favour the latter possibility. In the first place, rDNA replication at the onset of the macronuclear S-period has been described in cells which have been synchronized by an entirely different procedure, namely by starvation and refeeding, a procedure described by CAMERON and JETER (24). After 24 hours of starvation most cells are arrested at the GI/S boundary, and refeeding induces synchronous DNA replication followed by synchronous cell division $(180,96)$. Also these cells initiate DNA synthesis by replication of rDNA $(39,40)$. Furthermore, JAUKER et al. (60) recently measured the amount of tritiated uridine incorporated into RNA in pulses during a selection synchronized cell cycle, and they interpreted their results as measures of the rate of RNA synthesis. They found that this rate increases abruptly at the beginning of the macronuclear S-period and decreases prior to cell division. Ribosomal RNA represents more than 90 percent of the total RNA in Tetrahymena (70), so these results may suggest a "gene dose effect" of the ribosomal genes replicating early in the S-period. Also in heat synchronized Tetrahymena the rate of RNA synthesis has been found to double at the time when the ribosomal genes replicate (66).

One report describes a different timing of the rDNA replication in exponentially growing cells. CHARRET (26) incubated the cells for two hours with tritiated thymidine and prepared autoradiograms on which she found cells with two labelled micronuclei. In addition some label was incorporated into the nucleoli, whereas the macronuclear chromatin was unlabelled. The micronucleus divides and replicates its DNA at the time of the macronuclear and cellular division. This led CHARRET to conclude that the nucleolar DNA replicates within the last two hours of the cell cycle, the duration of which was 6 hours. This conclusion rests on the assumption that the strain of Tetrahymena used contains only one micronucleus behaving as described above. Two or more micronuclei are frequently observed, so since this possibility has not been excluded, more experiments will be needed to confirm this observation.

\section{DNA REPLICATION AND CELL DIVISION}

It has been mentioned that cells synchronized with one heat shock per cell generation exhibit a well ordered DNA replicationdivision cycle. The cell divisions are followed by synchronized DNA replication, itself a prerequisite for the following division. If DNA synthesis is arrested from the beginning, or from early in the S-period, the cells fail to divide, and it seems to be a rule in most cells that when DNA replication is arrested before all DNA has been replicated the following cell division is prevented. However, synchronized Tetrahymena cells do divide if only a fraction of the macronuclear DNA has been replicated. This was observed in experiments in which DNA replication was arrested by thymidine starvation. This was achieved experimentally by use of methotrexate and uridine $(M+U)$ which inhibits both the endogenous and the exogenous supply of thymidine (see section 5.1. and ref. (117)). By addition of $M+U$ at various time

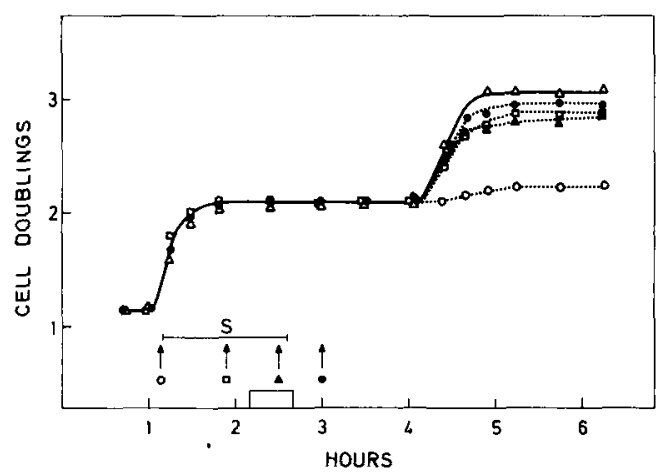

Figure 3. The effect of $M+U$ on cell division. $M+U$ was added at the time points indicated by arrows during and after the S-period. The S-period is indicated by a horizontal bar. (From ANDERSEN (6)). 
points during the cell cycle it was found (6) that the cells divided although the DNA replication was inhibited in the latter half of the normal Speriod (fig. 3). Measurements of the amount of DNA which was replicated in the various populations before the inhibition with $\mathrm{M}+\mathrm{U}$ became effective showed that replication of about 75 percent of the DNA in a population was sufficient for the cells to divide. However, the cells enter the S-period with some spread in time, and if we assume that this spread is the same as the spread with which the cells divide, then the individual cells have replicated between 60 and 90 percent of their DNA when 75 percent of the DNA in the population has been replicated. It is obvious that these calculations give only a rough estimate of the average excess of DNA in a macronucleus, but the figure agrees with CLEFFMANN'S (29) results for exponentially growing cells of strain HSM, which tolerate a considerable reduction of the average DNA content before any effect is observed on the level of cell divisions. This flexibility might possibly be related to the high degree of ploidy in the macronucleus of these cells. If, as was previously suggested, units of the size of haploid genomes are replicated out of phase, then some, perhaps most, of these units may be fully replicated before the macronuclear S-period is over. This would ensure that each daughter cell possessed a full genetic equipment even if the preceding macronuclear S-period were to be prematurely interrupted, and regardless of the possibility that some of the genomes remained unreplicated.

Experiments on E.coli indicate that replication and translation of a specific terminal chromosome segment is necessary for the cell division $(55,78)$. Thus, a signal coupled to the end of the S-period initiates the division relevant processes. It has been suggested that such a signal is coupled to the end of the macronuclear S-period in Tetrahymena (22, 23 ), but it seems unlikely that any specific late replicating DNA fraction exists. Firstly, because DNA which replicates late in one $S$ period may replicate early in the next and vice versa, as described above. Secondly, because the latter part of the DNA replication can be in- hibited without any consequence for the cell division. However, the situation in Tetrahymena is reminiscent of that in E.coli which in rich medium contain excessive amounts of DNA. In these cells requirements for a single division are met as soon as a replicaton fork has passed the bacterial chromosome once. Subsequent inhibition of the DNA synthesis stops other replication forks but affects only later divisions $(27,51)$. Thus, in Tetrahymena it is possible that replication of a terminal segment of a single genome well ahead of the end of the macronuclear S-period, might deliver the signal for the following cell division. However, other evidence suggests that cell division does not depend on DNA replication in the preceding generation, and might suggest another possible mechanism for regulating the coupling between DNA and cell division. If a certain threshold value between DNA (measured as transcription level, in general or of a specific RNA) and some cell parameters (e.g. volume, mass or specific proteins) has to be exceeded for the cell to be triggered into division, this would explain how cells with a high amount of DNA (e.g. cells synchronized with a series of heat shocks prior to division) can go from one cell division to the next without interjacent DNA replication. Furthermore, bacterial cells have been described which are capable of continued growth and cell division even though DNA replication is blocked (B. subtilis, Salmonella and mutants of E.coli). Such cells divide and produce at each cell division one cell with DNA and capable of new divisions and one cell without DNA $(36,52,59$, 102). Apparently the nucleated cells have a transcription level high enough to keep growth and cell divisions going. These cells never reach a lower treshold level in DNA concentration, a level which makes new DNA replication a prerequisite for the next cell division. In an analogous manner the Tetrahymena cells may reach a threshold level of DNA before the end of the macronuclear S-period, and the rest of the DNA replication is not obligatory.

In accordance with the nomenclature of Howard and Pelc (57), the cell cycle is composed of G1, S and G2-periods, and these terms have been used in the present paper. $S$ stands 
for synthesis of DNA and the G stands for gaps in this synthesis. Later work has shown that the G-periods are characterized by other specific events, which may have a causal relationship with the DNA replication. In Tetrahymena FRANKEL (45) has described a series of structural changes related to the development of the new oral apparatus, and these are considered typical G2 activities. However, BUHSE and ZEUTHEN (21) showed that these G2 activities and the DNA replication can overlap in time. Furthermore, they observed that occasionally synchronized Tetrahymena cells are born with a oral primordium in stage 1 (45). An oral primordium in stage 1 would normally develop to stage 6 in 30-40 minutes. However, in these cells this development is repressed for about 40 minutes covering the first two-thirds of the macronuclear S-period. Thus, morphogenesis shows derepression at that time in the S-period when inhibition of the DNA replication can no longer inhibit cell division. The oral primordium resumes its development parallel with the replication of the last one-third of the macronuclear DNA. In summary, one might suggest that the obligatory DNA replication represses $G 2$ events which are coupled with cell division, and that de-repression may occur before the DNA is fully replicated.

\section{ELIMINATION OF NUCLEAR DNA}

\subsection{The Inhibition of DNA synthesis}

Addition of methotrexate plus uridine $(\mathrm{M}+\mathrm{U})$ causes thymidine starvation in the cells, and stops DNA synthesis within about 10 minutes. The combination of $M$ and $U$ was introduced by ZEUTHEN (117) as a specific inhibitor of the DNA synthesis in cells grown on a medium containing thymidine. The proteosepeptone-liver extract medium used for cultivating Tetrahymena contains about 0.2 mM-thymidine (85). In high concentration uridine is an effective competitive inhibitor of the utilization of thymidine from the medium, but it is not known whether uridine competes with thymidine at the level of uptake or phosphorylation, or both.

Methotrexate is a folic acid analogue which i.a. blocks the function of the tetrahydrofolic acid dependent thymidylate synthetase. In short-term experiments, i.e. for about one cell generation, $M+U$ was found to have little effect on RNA and protein synthesis (110), and during this period $M+U$ is a very specific inhibitor of the DNA synthesis. However, $\mathrm{M}+\mathrm{U}$ has an indirect effect on the RNA synthesis, since the doubling in rate of ribosomal RNA synthesis, which in synchronized cells occurs at the time when the ribosomal genes (rDNA) are replicated, is prevented when $\mathrm{M}+\mathrm{U}$ blocks the replication of rDNA (66).

After long treatment with $M$ unspecific effects are seen. One possible target for the methotrexate is the mitochondrial protein synthesis, where polypeptide chain initiation is dependent on the formation of $\mathrm{N}$-formylmethionine. The formyltransferase is inhibited by methotrexate. NEX $\emptyset$ and ZEUTHEN $(85,121)$ have studied the effect of $M+U$ on the nucleotide triphosphate pools and found that addition of $\mathrm{M}+\mathrm{U}$ in the nuclear $\mathrm{S}$-period empties the thymidine triphosphate pool within few minutes. Addition of $M+U$ outside the $S-$ period maintains the thymidine triphosphate at a constant level, and prevents the increase which is normally seen before initiation of the DNA replication. As soon as the S-period begins, the pool is emptied of thymidine triphosphate. These results agree well with the estimation of how fast $M+U$ inhibits the DNA replication (6).

\subsection{Elimination of Macronuclear DNA in Tetrahymena}

As described above, inhibition of DNA replication in the latter half of the macronuclear S-period does not affect the following cell division. Cells treated in this way divide, even though they contain a fraction of DNA which is only partially replicated, namely the DNA fraction which was in replication at the time when the inhibitor became effective. This partially replicated DNA fraction was labelled specifically by adding tritiated thymidine shortly before the $\mathrm{M}+\mathrm{U}$. Autoradiography of these cells, fixed at various time points before, at, and after the next cell division showed that the labelled DNA was localized in the nucleus until the nucleus 

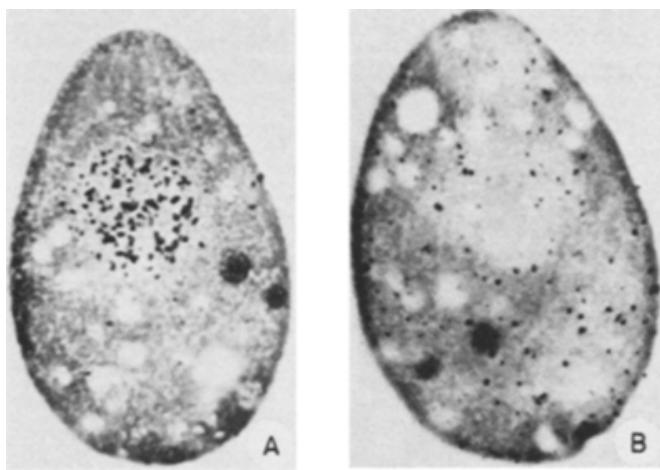

Figure 4. Autoradiograms of cells labelled with tritiated thymidine prior to inhibition of the DNA replication with $M+U$. (A): cell which has been fixed before the next cell division. (B): cell fixed in the subsequent cell generation. (From ANDERSEN (5)).

divided. At this time most or all of the labelled DNA became dispersed all over the cytoplasm, see figure 4 (5). In contrast, DNA which had been pulse-labelled early in the S-period, well before the addition of $M+U$, remained in the nucleus after the division. Thus, DNA which is not fully replicated when the cell enters division, and only this DNA, will not take part in the normal segregation, and a considerable fraction of the nuclear DNA can thereby be lost from the nucleus. The cell can tolerate this loss of DNA, probably because some genomes are fully replicated at the time when inhibition of the DNA replication can no longer inhibit the cell division.

\subsubsection{Extrusion bodies in Tetrahymena}

The induced elimination of DNA described above differs in some respects from the previously well described phenomenon of DNA extrusion in the form of extrusion bodies (29, $37,79,99)$. DNA eliminated in bodies is left behind between the parting daughter nuclei in the form of Feulgen-positive granules, and mostly so in cells overloaded with DNA though sometimes also in undisturbed log-phase cells. The size of an extrusion body seems to be positively correlated with the amount of DNA in the nucleus prior to the division. Furthermore, in contrast to the DNA eliminated after $M+U$ treatment, the DNA of a normal extrusion body appears to represent a random fraction of the DNA in the nucleus. Prior to its elimination from the nucleus this DNA takes part in the replication proces, but after its extrusion it no longer replicates (37, 13), and also in this latter respect it differs from DNA which becomes eliminated in response to blockage of DNA replication (see 5.3.). Generally extrusion bodies are resorbed before the next division.

In spite of such recognized differences between the two phenomena they may well be of common nature. As it will appear from the following (5.2.2. and 5.2.3.) elimination of nuclear DNA has also been described in other cell types. It seems to be characteristic of the eliminated DNA that it has either been damaged (e.g. by UV- or X-ray irradiation or by chemical treatments) or that it has been replicated late relative to the onset of the next cell division. It was mentioned above (4.) that the polyploid macronucleus possesses the capacity to permit initiation of division related processes before the S-period has been terminated. In Tetrahymena there is an inverse correlation between the cell size at birth and the time till the next cell division (77), a correlation which extends to oversized heat shock synchronized cells which have a shortened generation time after termination of the heat treatment $(116,121)$. It therefore seems possible that cells with a high DNA content start cell division relatively early after the termination of DNA replication, and that late replicating DNA may not have time to condense properly before the division. In the macronucleus such DNA always represents a random fraction of the DNA, because of the mixing of the DNA between two S-periods, as was described in section 3.2.1.. The apparent difference with respect to continued replication in the cytoplasm of DNA eliminated after $\mathrm{M}+\mathrm{U}$ treatment and DNA in extrusion bodies has been alluded to above. Whereas extrusion bodies may contain DNA which finished replication in the nucleus prior to its elimination, the $\mathrm{M}+\mathrm{U}$ treatment causes elimination of DNA which seems to contain some partially single stranded molecules (section 5.3.). This has a possible parallel in the different reaction 
of oocyte cytoplasm to injected native and single stranded DNA, respectively, as has been described by GURDON and co-workers (section 5.3.2.).

\subsubsection{Chromosome elimination after cell fusion}

A macronucleus in which replication has been blocked during the latter half of the Speriod may share features with a synkaryon produced by fusion of a mitotic and of an Sphase HeLa cell nucleus, such as described by RAO and Johnson $(64,93,94)$. It was found that the mammalian hybrid nucleus and cell would divide even though the chromosomes from one of the original cells still represented the Sphase. The cell in mitosis, thus containing condensed chromosomes, forced the S-phase chromosomes to condense prematurely. However, such chromosomes do not condense properly. Instead they fragment, fail to take part in normal chromosome segregation, and they are lost from the nucleus at the time of its division.

When the $M+U$ treated macronucleus of Tetrahymena enters into division it contains both fully- and partially replicated chromatin units. It is here suggested that fully replicated DNA takes part in the chromatin condensation prior to the cell division as it has been described by NILSSON $(86,87)$, and that DNA blocked in replication does not. At the cell division the latter fraction of the macronuclear DNA might thus be forced into premature chromatin condensation and be extruded from the macronucleus.

\subsubsection{Cytoplasmic DNA in other cell types}

There are a number of observations which indicate that damaged nuclear DNA can be extruded to the cytoplasm.

Elimination of DNA from the two macronuclei in Stylonychia can be induced by $X$-ray or ultraviolet light as described by AmmermanN (4). The macronuclei persist but the micronuclei are destroyed by the treatment. After some time the cells resume growth and small cytoplasmic particles appear which are named pseudomicronuclei and contain DNA originating from the macronucleus. The DNA in these particles undergo replication, but the pseudomicronuclei can not function as micronuclei in conjugation, and the cells eventually die.

A related penomenon has been described in DON chinese hamster cells after irradiation-induced chromosome aberration (58). The irradiation effect of tritiated thymidine after incorporation into the cells DNA resulted in the appearance of micronuclei. This extruded DNA replicates, but out of phase with the nuclear DNA, and there is high incidence of pulverized chromosomes originating from the micronuclei.

Using electron microscopic autoradiography NAKAI et al. (83) found incorporation of tritiated thymidine in a cytoplasmic, nonmitochondrial fraction of DNA in 90-Sr-induced chloroleukemic cells from rats. This cell line is induced by a DNA damaging treatment, and it is likely that a correlation exists between damage and the later appearance of a cytoplasmic DNA fraction.

Recently, BELL et al. (14) have studied the DNA synthesis in friend leukemic cells, and they suggested that these cells possess a mechanism for transfer of chromatin subunits from the nucleus to the cytoplasm.

Thus, what to this author was first a rather special phenomenon of DNA elimination from a ciliate macronucleus, might perhaps be a phenomenon of general biological significance, and one can speculate if it has features in common with the formation of oncogenic viruses which may arise by excision of genes from the host cell genome $(106,31)$.

\subsection{Replication of Eliminated Macronuclear DNA}

Inhibition of the DNA replication by $\mathrm{M}+\mathrm{U}$ may be terminated by transfer of the cells to fresh growth medium. Therefore, when the cells were treated with $M+U$ in the latter half of a synchronous $\mathrm{S}$-period as described above (section 5.2.), and transferred to fresh medium at the time of the following cell division, they were found to initiate the next round of DNA replication and to continue growth. Such cells carry a fraction of partially replicated DNA of which some or most has been transferred from 
the nucleus to the cytoplasm. In other cell types mentioned in section 5.2.3. eliminated nuclear DNA was found to replicate further in the cytoplasm, and it became of obvious interest to study whether this was the case also in Tetrahymena. Therefore, elimination of macronuclear DNA was induced in one cell cycle, and the DNA replication was followed during the next cell cycle by pulse-labelling with tritiated thymidine. Autoradiograms showed that a non-mitochondrial DNA synthesis took place in the cytoplasm late in the second cell cycle (7). A series of experiments was performed to elucidate the nature of this cytoplasmic DNA synthesis.

A priori, release of the blocked DNA replication could lead to new synthesis, as measured by incorporation of $\mathrm{BUdR}$, of any of the following types: 1) repair synthesis of DNA damaged by $\mathrm{M}+\mathrm{U}$, 2) breakdown of the extruded DNA and reutilization of labelled thymidine, 3) re-initiation of DNA synthesis and 4) continuation of the blocked replication. In the first two cases the tritium labelled thymidine which was incorporated during the first cell cycle, and the BUdR label which was incorporated during the next cell cycle would become built into and mixed within the same DNA strand. Such single stranded DNA should form only one band in alkaline cesium chloride gradients, but this was not observed, which eliminates possibilities 1) and 2). The possibility remains that the two labels - BUdR and tritiated thymidine - are in the same strand, though not mixed. They might be present selectively over long stretches, permitting separation of heavy from light DNA after the molecular shearing which accompanies the isolation of DNA. This interpretation of the results is compatible with possibility 4), namely that the inhibited DNA replication simply continues after the inhibitor is removed. However, further experiments were designed to distinguish between possibilities 3) and 4). In these experiments the eliminated DNA was pulselabelled with $B U d R$ prior to the $M+U$ treatment, and again labelled with BUdR during the continued replication in the cytoplasm. If the blocked replication was re-initiated in the cytoplasm, then extruded BUdR labelled DNA should function as template in replication occurring in the presence of BUdR, and double heavy DNA should accumulate, but this was not found. In these experiments the continued replication of BUdR-labelled, extruded DNA tended to form DNA of only hybrid density as should be the case if the replication represents simple elongation of the previously BUdRlabelled DNA strand. Also this experiment indicates possibility 4), but excludes 3 ) (7). In re-

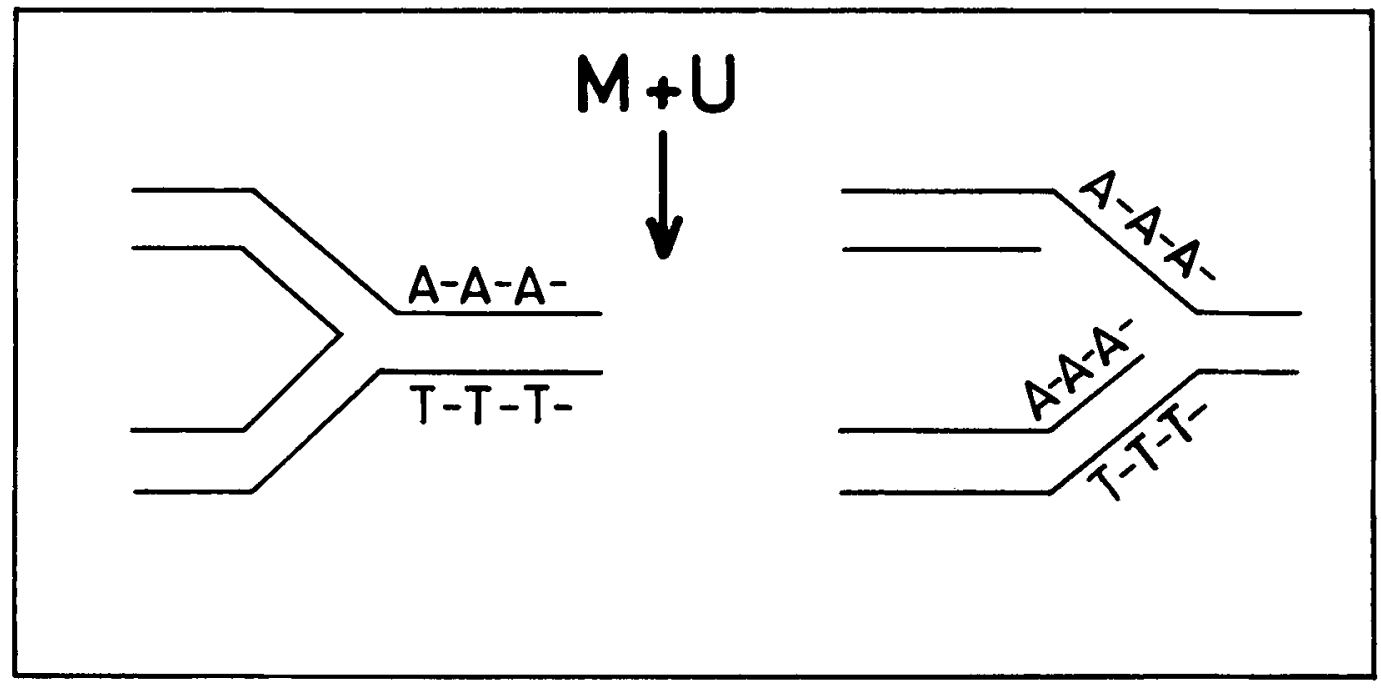

Figure 5. The proposed effect of $\mathrm{M}+\mathrm{U}$ on replicating DNA. The replication is blocked in a region rich in dAdT, leaving a partially replicated molecule with single strands rich in adenosine. (From ANDERSEN and KEIDING (12)). 
cent experiments we have extended this conclusion. When DNA was isolated shortly after inhibition with $M+U$ and centrifuged in cesium chloride gradients, it was found that DNA which was stalled in replication contained a minor fraction of relatively high buoyant density. However, after continuation of the replication in the subsequent cell cycle this fraction disappeared and a low buoyant density fraction appeared. DNA with low buoyant density in cesium chloride is relatively rich in $\mathrm{dAdT}$, and we have interpreted these results to mean that thymidine starvation, here caused by $\mathrm{M}+\mathrm{U}$, stops DNA replication preferentially in regions of the molecules with high dAdT content, leaving the $\mathrm{dA}$ rich DNA strand partially single stranded, and therefore of relatively high buoyant density (see figure 5). When such molecules after extrusion from the nucleus continue replication in the cytoplasm a dAdT rich DNA fraction is formed which may be labelled specifically during its replication in the G2period, and which forms a low buoyant density fraction in cesium chloride (12).

In conclusion, it is suggested that thymidine starvation caused by $\mathrm{M}+\mathrm{U}$ creates a fraction of partially replicated DNA, perhaps with stretches of single strands rich in deoxyadenosine. Furthermore, that this DNA fraction can continue the previously blocked replication in a cytoplasmic location after release from the inhibitor. Whether such DNA remains and replicates further in the cytoplasm, whether it is expelled from the cell or perhaps returns to the nucleus remains unknown.

\subsubsection{Replication and transcription of mammalian genes not located on the chromosomes}

Cell fusion experiments have shown that genes from mammalian cells may continue to replicate and to be transcribed although apparently no longer located on the chromosomes. HARRIS and co-workers (18, 101) showed that clones of heterokaryons formed by fusion of chick erythrocytes with chinese hamster cells lacking inosinic acid pyrophosphorylase, or with mouse cells lacking thymidine kinase, could be grown in selective media in which possession of the two enzymes mentioned was essential. In other words, the chick erythrocyte nucleus supplies the active genes for the two necessary enzymes. However, occasionally clones of the heterokaryons were found to grow on the selective media although no chick chromosomes could be detected in the nucleus or any chick-specific antigens could be detected on the surface of the cells. The authors suggested that the reactivated chick erythrocyte nucleus underwent premature chromosome condensation or chromosome pulverization, and that fragments of the pulverized genetic material remained in the cells as active genes. The location in the cells of these chromosome fragments has not been detected, and they might stay in the nucleus. However, on the basis of what has been described we might also propose that such fragments could remain active in the cellular cytoplasm.

\subsubsection{Replication of injected DNA in oocyte and egg cytoplasm}

The examples of cytoplasmic DNA mentioned so far all represent dislocation of the cell's own nuclear DNA. However, replication of foreign DNA in the cytoplasm has also been described. GURDon et al. (50) found that injection of whole foreign nuclei into an unfertilized amphibian egg induced DNA synthesis in the injected nuclei, and furthermore that injection of purified DNA of any kind into the egg cytoplasm induced this DNA to replicate in the cytoplasm about 20 minutes after the injection.

In experiments with purified polyoma virus DNA, LASKEY and GURDON (69) found the induced replication to be semi-conservative. Whereas the egg cytoplasm can induce replication of both native double stranded DNA and single stranded DNA, the oocyte cytoplasm can only induce replication of single stranded DNA, and not of the native DNA (49). When single stranded DNA was injected into either egg or oocyte cytoplasm the replication was initiated without any lag.

It should be noted here that DNA extruded into the cytoplasm of Tetrahymena by way of normal extrusion bodies does not replicate further in the cytoplasm (section 5.2.1.), whereas DNA which is transferred to the cytoplasm after $M+U$ treatment does 
replicate again. Furthermore, the first material is not likely to contain unusual amounts of single stranded DNA whereas the second may well be so characterized. Thus, it seems that the cytoplasm of Tetrahymena cells may have a capacity for the induction of DNA replication comparable to that of Xenopus oocyte cytoplasm.

\section{EFFECTS OF 5-BROMODEOXYURI- DINE: PREFERENTIAL INHIBITION OF rDNA TRANSCRIPTION BY BUdR}

Five-bromodeoxyuridine (BUdR) has been used to density label DNA in most of the replication studies reported in the present paper. In combination with density gradient techniques this compound has been widely used as a valuable tool in cell biological research. However, BUdR has a number of cytotoxic effects on higher cells, and it inhibits differentiation at some stage of development in all systems studied so far (for review see (97)). On this background we decided to examine in some detail the possible effects of BUdR on Tetrahymena, and it appeared that this cell may be particularly suitable for studies of the molecular basis of the BUdR effects. It was shown for the first time that the presence of BUdR in the DNA may inhibit the transcription of certain genes.

It should be pointed out that under most growth conditions Tetrahymena cells can multiply for hundreds of generations in the presence of BUdR, and in the studies reported in the present paper the incorporation of $B U d R$ into DNA did not measurably affect the DNA replication. However, the RNA synthesis is affected at even a low degree of substitution, and after few generations the cell generation time is slightly extended. Under special growth conditions as outlined below the substitution of TdR with BUdR in the nuclear DNA may reach such a level as to cause cessation of cell proliferation and severely affect macromolecular metabolism. $(73,74,75,76)$.

The extent of BUdR substitution in the DNA of Tetrahymena is highly dependent on the growth conditions of the cells. The thymidine necessary for the DNA synthesis may either be synthesized endogenously with tetrahydrofolic acid as a cofactor, or the cells may take up thymidine from the medium. The concentrations of tetrahydrofolate and thymidine are therefore of the utmost importance for the amount of BUdR incorporated. In order to control these concentrations, the cells were grown on a fully defined medium without thymidine (95), but with a defined concentration of tetrahydrofolate in order to regulate the endogenous synthesis of thymidylate. Tetrahydrofolic acid is a cofactor in other metabolic reactions (formation of $\mathrm{N}$-formyl-methionine in the mitochondria has been mentioned above), and a minimum concentration of tetrahydrofolate is therefore necessary to sustain growth. At the same time this defines upper limits for the BUdR substitution in DNA. The generation time of the cells will be highly dependent on the composition of the defined medium, and it was of importance to define growth conditions which have reasonable short and well defined generation times, and at the same time secured high incorporation of BUdR into DNA. Thus, the growth was limited by the concentration of tetrahydrofolate in the medium, and a correlation between BUdR substitution in DNA and the tetrahydrofolate concentration was established $(72,75)$.

At a tetrahydrofolate concentration of $7 \mathrm{ng} /$ $\mathrm{ml}$ the generation time of the cells was four to five hours. In such cultures BUdR in $0.8 \mathrm{~mm}$ concentration gave substitution in about 60 percent of the thymidine sites in DNA. Measurements of DNA, RNA and protein synthesis showed that whereas RNA synthesis was strongly inhibited within the first cell generation, the DNA replication was unaffected and protein synthesis only slightly reduced over two cell generations $(73,75)$. This rapid and preferential effect on RNA synthesis is probably indirect and mediated by substitution of $\mathrm{TdR}$ with BUdR in DNA. This was demonstrated by use of synchronized cells in which the effect of BUdR on RNA synthesis could be studied without simultaneous DNA synthesis. Neither in populations synchronized with heat shocks nor by starvation/refeeding has the presence of BUdR any effect on the RNA synthesis when no 


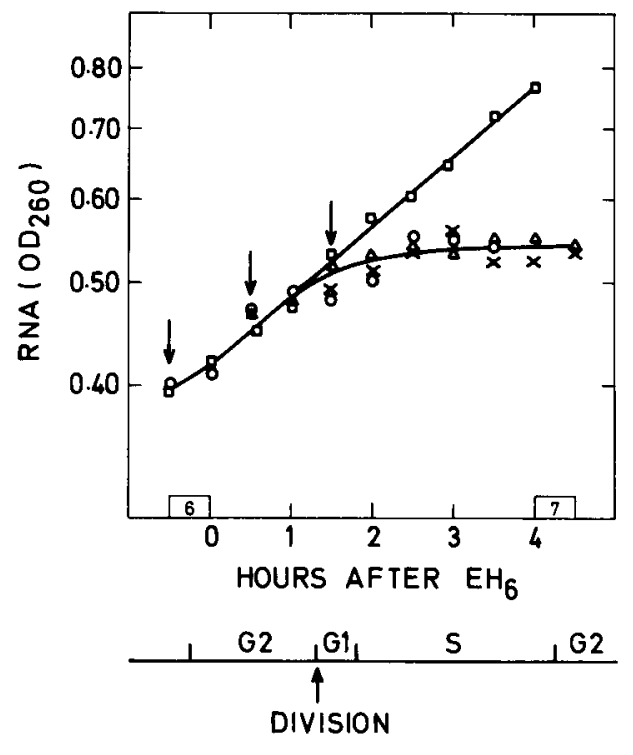

Figure 6. Relative amount of RNA as a function of time. The arrows indicate the addition of BUdR $(0.8$ $\mathrm{mm})$ to subcultures $(O, \triangle, x)$. The control $(\square)$ was treated with $0.8 \mathrm{~mm}-\mathrm{TdR}$. The cell cycle is indicated at the lower part of the figure. (From LyKKesfeld and ANDERSEN (75)).

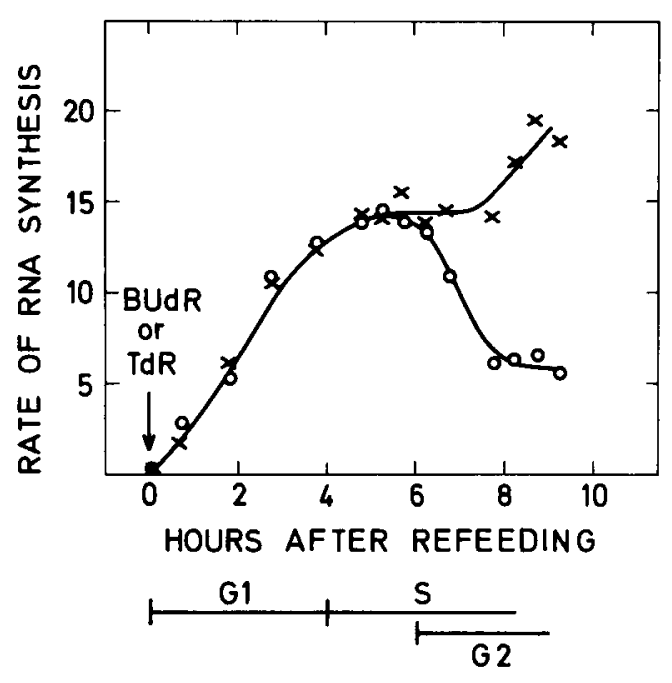

Figure 7. Rate of RNA synthesis measure as 14-Curidine incorporation during a 30 minutes pulse (cpm $\left.\times 10^{-2}\right)$ as a function of time after refeeding. BUdR culture: $(0)$, TdR culture $(x)$. The cell cycle is indicated at the lower part of the figure. (From LYKKESFELDT and ANDERSEN (75)).
BUdR has yet been incorporated into the nuclear DNA. This may be seen from the results presented in figures 6 and 7. Figure 6 shows the relative amount of RNA in heat synchronized cells as a function of time, with or without BUdR present. It may appear that the rate of RNA synthesis reduces sharply at the time when the cells initiate macronuclear DNA replication in the presence of BUdR. The effect on RNA synthesis is the same whether BUdR was added just prior to the macronuclear S-period or was added one or two hours earlier. Similar results were obtained with cells synchronized by starvation/refeeding as seen in figure 7 . Again the rate of RNA synthesis is unaffected by BUdR until the time when macronuclear DNA replication is initiated. As outlined in section 3.2.2., the DNA replication in both of these synchronized populations begins with the replication of the genes for ribosomal RNA. Based on these and previous results we have suggested that the presence of high amounts of BUdR in these genes causes a structural change of the DNA (73) resulting in inhibition of the transcription. In Tetrahymena the ribosomal RNA amounts to about 90 percent of the total RNA (70), and reduction in the amount of this single gene product could therefore be measured as a change in total RNA. However, by sucrose gradient separation of the various types of RNA it has been possible to measure more directly the reduction in the rate of ribosomal RNA synthesis (17S- and 25S RNA) relative to the synthesis of 4-5S RNA. Figure 8 shows the results from such experiments, which support the view that the observed effect of BUdR on total RNA synthesis reflects preferential inhibition of rDNA transcription (76).

Thus, we may conclude that the presence of BUdR in DNA can inhibit the transcription, and that some genes are more sensitive than others in this respect, possibly because of differences between the various genes in the degree of BUdR substitution, and differences from gene to gene with respect to the distribution of BUdR along the DNA strand(s). We have suggested that the presence of BUdR in DNA causes structural changes which influence transcription (73) but other mechanisms are equally well possible. LIN and 


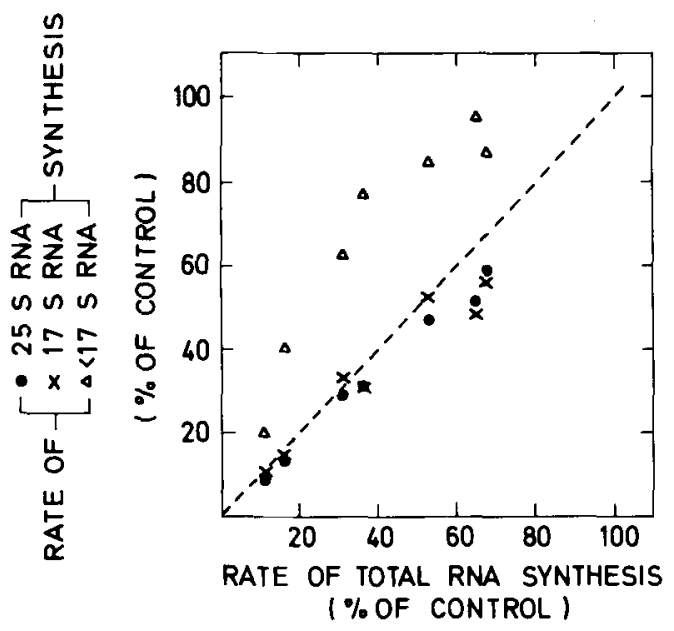

Figure 8. Preferential inhibition of $17 \mathrm{~S}$ - and 25S RNA. synthesis by BUdR. It may be seen that the rate of synthesis of $17 \mathrm{~S}$ - and $25 \mathrm{~S}$ RNA $(\bullet, x)$ follows the rate of total RNA synthesis, whereas RNA's $<17 \mathrm{~S}$ are much less affected $(\Delta)$. From LYKKESFELDT and ANDERSEN $(75,76))$.

RIGGS (71) showed that the lac repressor binds far more effectively to poly (dA-BUdR) than it does to poly (dAdT), and DAvID et al. (32) found that the presence of BUdR changes the melting profile of chromatin, again indicating that BUdR alters the dissociation constant of the DNA binding proteins. If these proteins are involved in the regulation of gene activity, this might explain why the presence of BUdR in DNA can inhibit transcription.

\section{SUMMARY AND CONCLUDING REMARKS}

The macronuclear DNA replication in Tetrahymena pyriformis has been studied in synchronized populations, using the thymidine analogue 5-bromodeoxyuridine as a marker of synthesized DNA. This density labelling of the DNA, followed by gradient centrifugation was used not only to measure the DNA replication as such, but also to gain information about the nature of DNA synthesis which takes place at various periods of the cell cycle.

In cells synchronized with seven heat shocks prior to the cell division, the DNA replication was followed during the heat treatment, and during the following period in which two synchronized cell divisions takes place. It was demonstrated that all DNA in the population was fully replicated during the heat treatment, and it was found that only about 50 percent of the cells replicated DNA between the first and the second synchronized division. These results confirm previous conclusions by ZEUTHEN and co-workers $(53,124)$ based on autoradiographic and chemical measurements, and they exclude the possibility that a fraction of the macronuclear DNA should fail to replicate during the heat treatment as has been suggested $(22,23)$.

Most of the work reported here deals with cells growing synchronously for many generations, and synchronized with one heat shock per cell generation. In such cells it was found that the DNA replication was initiated immediately after the cell division, and that all DNA in the population was replicated within the duration of a normal S-period i.e. about 60 minutes in the single cell plus the period of 2030 minutes within which the population divides.

In the synchronized S-period all DNA is replicated fully, once per cell generation, and after a fixed sequence which ensures that no double replication takes place. However, the replication sequence for the bulk of the macronuclear DNA changes from generation to generation. Only a minor fraction of the DNA localized in the nucleoli, the genes coding for ribosomal RNA, replicates each generation in a short period at the beginning of the macronuclear S-period.

Inhibition of the macronuclear DNA replication at various time points during the S-period showed that inhibition of the replication during the latter half of the S-period has no effect on the following cell division. This is discussed in relation to control mechanisms in the cell cycle, and in relation to the organization of the macronuclear DNA.

Some of the events in the synchronized cell cycle of Tetrahymena which have been described are shown schematically in figure 9. After the cell division (A), the macronuclear DNA replication begins with replication of the ribosomal genes (B), indicated by short broken 
lines. Thereafter, the bulk nuclear DNA replicates. The subnuclei or clumps of chromatin granules, each of which possibly represents a haploid genome, are indicated by fully drawn lines. Replication of a single unit may probably follow a fixed program in each replication round. However, the time of replication of these units relative to each other then change from generation to generation. In other words, the units replicate in asynchrony in each S-period, and replication of a single unit takes only a fraction of the macronuclear Speriod. The replication of the ribosomal genes has no fixed temporal relation to the replication of the single chromatin units. A particular unit might in the S-period replicate in close temporal relation with the replication of the nucleolar DNA, and in another S-period the same events might be separated by a long period. Our results do not directly contribute to the solving of the problem of whether the macronuclear subnuclei represent haploid genomes as was discussed in section 2. For further discussion of these problems, see Doerder (34) Doerder and Debault (35) and SONNEBORN (103). However, it should be emphasized that all the macronuclear DNA is replicated semiconservatively once per cell generation, and that no difference in buoyant density between early- or late replicating bulk
DNA could be measured. The cells are likely to have a full complement of replicated genes before the end of the macronuclear S-period. Obligatory DNA synthesis ends, and G2 activities are initiated when $70-80$ percent of the DNA has been replicated, at $(C)$ in figure 9.

When the cells divide after the DNA replication has been inhibited in the latter half of the preceding S-period, these cells divide with a fraction of their DNA only partially replicated. This DNA is eliminated from the macronucleus at the time of the division, and is found in the cytoplasm during the next cell generation. The extruded DNA was specifically labelled by addition of tritiated thymidine shortly before the inhibitory treatment, and the fate of this pulse-labelled DNA in the cytoplasm was followed during the next cell generation after release of the DNA synthesis. The extruded DNA remained in the cytoplasm during the following cell generation, and no change in this DNA was observed until the macronuclear DNA had finished replication. Then, in the G2period, the extruded DNA started to replicate, apparently by continuing the replication from the points in the DNA strands at which the process was inhibited in the preceding cell generation. Furthermore, from the experiments we have suggested that thymidine starvation, here used to inhibit DNA replication, tended to

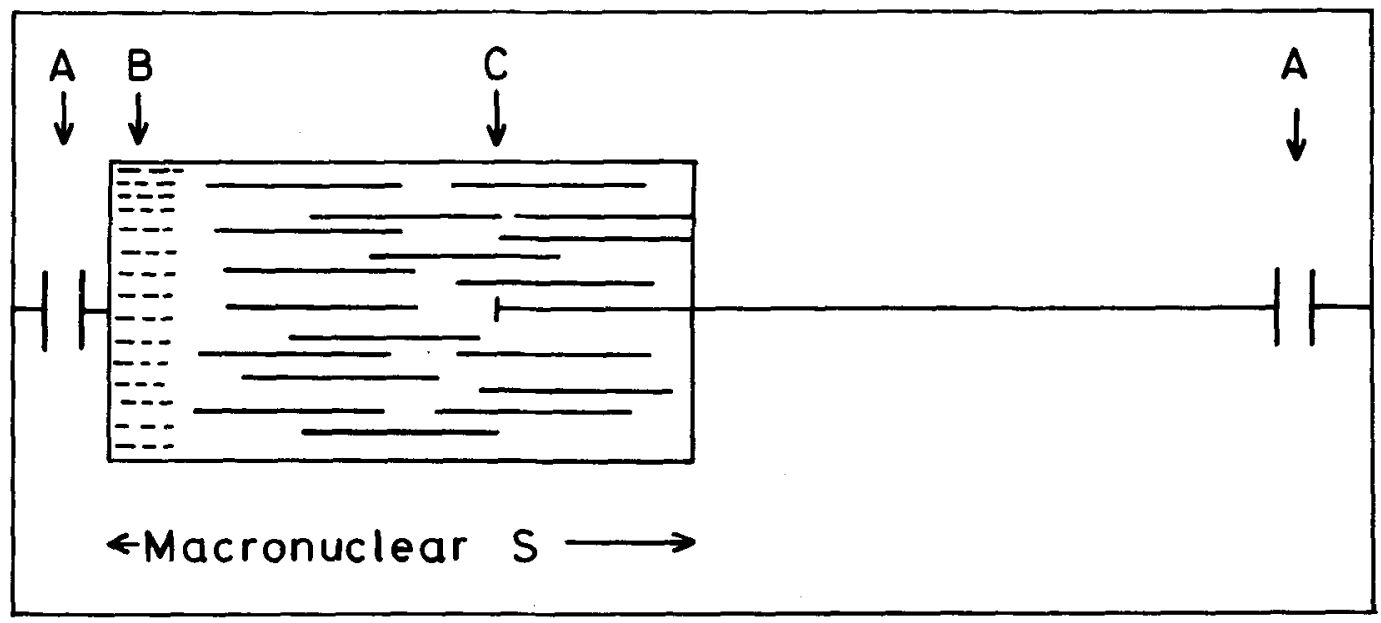

Figure 9. Events in the Tetrahymena cell cycle which have been discussed in the present paper. (A): cell division. (B): replication of the ribosomal genes (rDNA). (C): end of obligate DNA replication; initiation of G2-activities (morphogenic reactivation). The chromatin units which probabely represent haploid genomes are indicated by the horizontal lines. It is proposed that these units replicate in a new random order in each S-period. 
stop replication preferentially in $\mathrm{dAdT}$ rich regions of the molecules leaving single stranded regions of high deoxyadenosine content.

So far bromodeoxyuridine (BUdR) has been dealt with as a valuable tool for the analysis of DNA replication in Tetrahymena. However, under special circumstances this compound is a potent inhibitor of macromolecular synthesis and of cell proliferation. The last section of this review deals with our studies on such BUdR effects. BUdR must be incorporated into DNA in high amounts before inhibitory effects are seen. As soon as DNA contains BUdR in sufficient amounts this affects transcription, but the various genes respond differently to the substitution. The rDNA, i.e. the genes coding for the two large ribosomal RNA molecules (17S- and 25S RNA) was found to be most sensitive. As soon as these genes replicate in the presence of BUdR (in the synchronized populations at the beginning of the macronuclear $S$-period) this reduces the rate of transcription of these genes. It was concluded that the presence of BUdR may cause structural changes of DNA, and that such changes will inhibit transcription.

A highly polyploid macronucleus shows a number of features which can not be easily demonstrated in other eukaryotic cell types carrying normal chromosomal nuclei. Some of the phenomena here described may seem of special interest to protozoological research. On the other hand, it has been the intention in this review to correlate macronuclear phenomena with related phenomena in chromosomal cells, and it appears that the differences between cells which are most commonly catalogued differently and therefore studied by different groups are often quantitative rather than qualitative. Tetrahymena may appear to show in magnified form - nuclear phenomena of central significance for a number of different fields in cell biology. However, the magnification of chromosomal phenomena by polyploidization has a price, since at the same time the traditional genetic analysis of the cells becomes extremely difficult. The isolation of mutants, which has been of so great importance in cell biology, is only in its infancy with Tetrahymena. Although ciliates deserve an im- portant position in cell biological research further development of ciliate genetics is necessary, and will greatly improve the possibilities for further studies with these cells.

\section{ACKNOWLEDGEMENTS}

I wish to express my sincere gratitude to a number of persons who in various ways have contributed to this work. First and foremost I want to thank Professor ERIK ZEUTHEN, head of the Biological Institute of the Carlsberg Foundation, who introduced me to synchronized Tetrahymena cells, and strongly influenced this work through inspiring collaboration and innumerable discussions. For fruitful collaboration I want to thank everyone with whom I have published my work on Tetrahymena: Dr. C. F. BRUNK, Dr. JAN Engberg, Dr. Jens Keiding, Dr. Anne E. LYKKESFELDT and Dr. TøNNE TøNNESEN. I thank my colleagues at the Biological Institute for stimulating and pleasant discussions, and this also applies to the many guests from this country as well as from abroad.

I owe a debt of gratitude to the technical staff of the Biological Institute from whom I have received much help. Especially I wish to mention Ms. Grete Søger and Ms. Birgit HeltHANSEN who have rendered me excellent technical assistance, but several others have contributed directly to this work, and they have all through their kindness and pleasant ways helped to create a stimulating and pleasant atmosphere at the Biological Institute.

\section{REFERENCES}

1. Allen, S. \& I. Gibson: Genome amplification and gene expression in the ciliate macronucleus. Biochem. Gen. 6, 293-313 (1972)

2. Allen, S. \& I. Gibson: Genetics of Tetrahymena. In "Biology of Tetrahymena", Elliott, A. M., ed., Dowden, Hutchinson and Ross Inc., Pennsylvania. pp. 307-373 (1973)

3. Allen, S. L. \& D. L. Nanney: An analysis of nuclear differentiation in the selfers of Tetrahymena. Amer. Natur. 92, 139-160 (1958)

4. Ammermann, D.: Morphology and development of the macronuclei of the ciliates 
Stylonychia mytilus and Euplotes aediculatus. Chromosoma 33, 209-238 (1971)

5. ANDERSEN, H. A.: Induced elimination of DNA from the macronucleus of Tetrahymena pyriformis. Exptl. Cell Res. 74, 610-613 (1972)

6. ANDERSEN, H. A.: Requirements for DNA replication preceding cell division in Tetrahymena pyriformis. Exptl. Cell Res. 75, 8994 (1972)

7. ANDERSEN, H. A.: Replication of macronuclear DNA in the cytoplasm of Tetrahymena pyriformis. J. Cell Sci, 14, 289-300 (1974)

8. Andersen, H. A., C. F. Brunk \& E. Zeuthen: Studies on the DNA replication in heat synchronized Tetrahymena pyriformis. Compt. Rend. Trav. Lab. Carlsberg 38, 123-131 (1970)

9. Andersen, H. A. \& E. Zeuthen: DNA replication sequence in Tetrahymena is not repeated from generation to generation. Exptl. Cell Res. 68, 309-314 (1971)

10. Andersen, H. A. \& J. Engberg: Timing of the ribosomal RNA gene replication in Tetrahymena pyriformis. Exptl. Cell Res. 92, 159-163(1975)

11. Andersen, H. A., L. Rasmussen \& E. Zeuthen: Cell division and DNA replication in synchronous Tetrahymena cultures. In "Current Topics in Microbiology and Immunology". Arber, E. W. et al. eds., vol. 72, pp. 1-20, Springer Verlag, Berlin, Heidelberg, New York. (1975)

12. Andersen, H. A. \& J. Keiding: DNA replication in Tetrahymena after release from thymidine starvation. Carlsberg Res. Commun. 42, 153-162 (1977)

13. ANDERSEN, H. A. \& A. E. LYKKESFELDT: Unpublished observation

14. Bell, E., J. Lechner \& Charlotte Merrill: Synthesis of nuclear DNA in excess of the requirement for cell division. J. Cell Biol. 67, p. 25a. (1975)

15. Bostock, C. J. \& D. M. Prescott: Shifts in buoyant density of DNA during the synthesis period and its relation to euchromatin and heterochromatin in mammalian cells. J. Mol. Biol. 60, 151-162 (1971)

16. Bostock, C. J. \& D. M. Prescott: Buoyant density of DNA synthesized at different stages of S-phase in Chinese hamster cells. Exptl. Cell Res. 64, 481-484 (1971)

17. Bostock, C. J. \& D. M. Prescott: Buoyant density of DNA synthesized at different stages of the S-phase of mouse cells. Exptl. Cell Res. $64,267-274$ (1971)
18. Boyd, YvonNe L. \& H. HaRris: Correction of genetic defects in mammalian cells by the input of small amounts of foreign genetic material. J. Ceil Sci. 13,841-861 (1973)

19. Braun, R., C. Mittermayer \& H. P. Rusch: Sequential temporal replication of DNA in Physarum polycephalum. Proc. Natl. Acad. Sci. 53, 924-931 (1965)

20. Braun, R. \& H. WiLr: Time sequence of DNA replication in Physarum. Biochim. Biophys. Acta 174, 246-252 (1969)

21. Buhse Jr., Н. Е. \& E. Zeuthen: Oral morphogenesis in Tetrahymena cells synchronized with one heat shock per generation. Compt. Rend. Trav. Lab. Carlsberg 39, 493-505 (1974)

22. Byfield, J. E. \& Y. E. LeE: The effect of synchronizing temperature shifts on the synthesis and translation of replication supporting messengers in Tetrahymena pyriformis. Exptl. Cell Res. 61, 42-50 (1970)

23. Byfield, J. E. \& O. H. SCherbaum: Incomplete inhibition of synchronized cell division by Hydroxyurea and its relevance to the normal cellular life cycle. Nature 216, 1017-1018 (1967)

24. Cameron, I. L. \& I. R. Jeter: Synchronization of the cell cycle of Tetrahymena by starvationrefeeding. J. Protozool. 17,429-433 (1970)

25. Cameron, I. L. \& D. S. Nachtwey: DNA synthesis in relation to cell division in Tetrahymena pyriformis. Exptl. Cell Res. 46, 385-395 (1967)

26. Charret, R.: L'ADN nucléolaire chez Tetrahymena pyriformis: Chronologie de sa réplication. Exptl. Cell Res. 54, 353-361 (1969)

27. Clark, D. J.: The regulation of DNA replication and cell division in E. coli $B / r$. Cold Spring Harbor Symposia on Quantitative Biology, XXXIII, 823-838 (1968)

28. Clarkson, S. G. \& M. L. Birnstiel: Clustered arrangement of t-RNA genes of Xenopus laevis. Cold Spring Harbor Symposia on Quantitative Biology, XXXVIII, 451-459 (1973)

29. Cleffmann, G.: Regulierung der DNS-Menge im Makronukleus von Tetrahymena. Exptl. Cell Res. 50,193-207 (1968)

30. Cleffmann, G.: Amount of DNA produced during extra $\mathbf{S}$ phases in Tetrahymena. J. Cell Biol. 66, 204-209 (1975)

31. Comings, D. E.: A general theory of carcinogenesis. Proc. Natl. Acad. Sci. 70, 3324-3328 (1973)

32. David, J., J. S. Gordon \& W. J. Rutter: Increased thermal stability of chromatin containing 5-bromodeoxyuridine substituted DNA. Proc. Natl. Acad. Sci. 71, 2808-2812 (1974) 
33. Debault, L. E. \& N. R. Ringertz: A comparison of normal and cold synchronized cell divisions in Tetrahymena. Exptl. Cell Res. 45, 509-518 (1967)

34. Doerder, F. P.: Regulatory serotype mutations in Tetrahymena pyriformis, syngen 1 . Genetics 74, 81-106 (1973)

35. Doerder, F. P. \& L. E. Debault: Cytofluorimetric analysis of nuclear DNA during meiosis, fertilization and macronuclear development in the ciliate Tetrahymena pyriformis, syngen 1. J. Cell Sci. 17, 471-493 (1975)

36. Donachie, W. D., D. T. M. Martin \& K. J. BEGG: Independence of cell division and DNA replication in Bacillus subtilis. Nature, New Biology 231, 274-276 (1971)

37. Dysart, M. P.: Cytochemical and quantitative DNA analysis of the macronucleus and its extrusion body in species of Tetrahymena. J. Protozool. 10, suppl. p.8 (1963)

38. Engberg, J. \& R. E. Pearlman: The amount of ribosomal RNA genes in Tetrahymena pyriformis in different physiological states. Eur. J. Biochem. 26, 393-400 (1972)

39. Engberg, J., D. Mowat \& R. E. Pearlmann: Preferential replication of the ribosomal DNA genes during a nutritional shift up in Tetrahymena pyriformis. Biochim. Biophys. Acta 272, 312-320 (1972)

40. Engberg, J., J. R. Nilsson, R. E. Pearlmann \& V. LEICK: Induction of nucleolar and mitochondrial DNA replication in Tetrahymena pyriformis. Proc. Natl. Acad. Sci. 71, 894-898 (1974)

41. Engberg, J., G. Christiansen \& V. Leick: Autonomous rDNA molecules containing single copies of the ribosomal RNA genes in the macronucleus of Tetrahymena pyriformis. Biochem. Biophys. Res. Commun. 59, 13561365 (1974)

42. Engberg, J., P. Andersson, V. Leick \& J. Collins: The free rDNA molecules from Tetrahymena pyriformis, GL are giant palindromes. J. Mol. Biol. 104, 455-470 (1976)

43. Flamm, W. G., J. N. Bernheim \& P. E. BRUBAKER: Density gradient analysis of newly replicated DNA from synchronized mouse lymphoma cells. Exptl.Cell Res. 64, 97-104 (1971)

44. Flavell, R. A. \& I. G. Jones: Kinetic complexity of Tetrahymena pyriformis nuclear deoxyribonucleic acid. Biochem. J. 116, 115-157 (1970)

45. Frankel, J.: The effect of heat, cold and p-fluorophenylalanine on morphogenesis in syn- chronixed Tetrahymena pyriformis GL. Compt. Rend. Trav. Lab. Carlsberg 33, 1-52 (1962)

46. GALL, J. G.: Free ribosomal RNA genes in the macronucleus of Tetrahymena. Proc. Natl. Acad. Sci. 71, 3078-3081 (1974)

47. Gibson, I. \& I. MARTIN: DNA amounts in nuclei of Paramecium aurelia and Tetrahymena pyriformis. Chromosoma 35, 374-382 (1971)

48. Gorovsky, M. A. \& J. Woodard: Studies on nuclear structure and function in Tetrahymena pyriformis. 1. RNA synthesis in macro- and micronuclei. J. Cell Biol. 42, 673-682 (1969)

49. Gurdon, J. B.\& V. A. Speight: The appearance of cytoplasmic DNA polymerase activity during the maturation of amphibian oocytes into eggs. Exptl. Cell Res. 55, 253-256 (1969)

50. Gurdon, J. B., M. L. Birnstiel \& V. A. SPEIGHT: The replication of purified DNA introduced into living egg cytoplasm. Biochim. Biophys. Acta. 174,614-628 (1969)

51. Helmstetter, C. E. \& O. Pieruccl: Cell division during inhibition of deoxyribonucleic acid synthesis in Escherichia coli. J. Bacteriol. 95,1627-1633(1968)

52. Hirota, Y., A. RYter \& F. JACOB: Thermosensitive mutants of $E$. coli affected in the processes of DNA synthesis and cellular division. Cold Spring Harbor Symposia on Quantitative Biology, XXXIII, 677-693 (1968)

53. HJelm, K. K. \& E. Zeuthen: Synchronous cell division in Tetrahymena. Compt. Rend. Trav. Lab. Carlsberg 36, 127-160 (1967)

54. HJelm, K. K. \& E. Zeuthen: Synchronous DNA synthesis following heat-synchronized cell division in Tetrahymena. Exptl. Cell Res. 48, 231$232(1967)$

55. Hoffmann, B., W. Messer \& U. Schwartz: Regulation of polar cap formation in the life cy. cle of Escherichia coli. J. Supramol. Structure 1, 29-37 (1972)

56. HoLm, B. F.: Changes in the amount of DNA in synchronized cultures of Tetrahymena cells. Exptl. Cell Res. 53, 18-36 (1968)

57. Howard, A. \& S. R. Pelc: Synthesis of deoxyribonucleic acid in normal and irradiated cells and its relation to chromosome breakage. Heredity, London. (Suppl.) 6,261-273 (1953)

58. IKeuchi, T., H. Weinfeld \& A. A. Sandberg: Chromosome pulverization in micronuclei induced by tritiated thymidine. J. Cell Biol. 52, 97. 104 (1972)

59. INOUYE, M.: Pleiotropic effect of the rec A gene of Escherichia coli: uncoupling of cell division from deoxyribonucleic acid replication. J. Bacteriol. 106, 539-542 (1971) 
60. JaUker, F., H. M. Seyfert \& J. SGonina: Temperature dependent changes of cell growth parameters in Tetrahymena. Exptl. Cell Res. 96,439-442 (1975)

61. JeFFERY, W. R.: Evidence for a temporal incompatibility between DNA replication and division during the cell cycle of Tetrahymena. J. Cell Biol 53, 624-634 (1972)

62. Jeffery, W. R., J. Frankel, L. E. Debault \& L. M. JENKINS: Analysis of the schedule of DNA replication and cell division in heat-synchronized Tetrahymena. J. Cell Biol. 59, 1-11 (1973)

63. Jeffery, W. R., K. D. Stuart \& J. Frankel: The relationship between deoxyribonucleic acid replication and cell division in heat-synchronized Tetrahymena. J. Cell Biol. 46, 533-543 (1970)

64. Johnson, R. T. \& P. N. Rao: Mammalian cell fusion: induction of premature chromosome condensation in interphase nuclei. Nature 226 , 717-722 (1970)

65. Karrer, K. M. \& J. G. Gall: The macronuclear ribosomal DNA of Tetrahymena pyriformis is a palindrome. J. Mol. Biol. 104, $421-453$ (1976)

66. Keiding, J. \& H. A. ANdersen: Regulation of ribosomal RNA synthesis in Tetrahymena pyriformis. In prep.

67. Kimball, R. F. \& D. M. Prescott: Deoxyribonucleic acid synthesis and distribution during growth and amitosis of the macronucleus of Euplotes. J. Protozool. 9,88-92 (1962)

68. KIMMEL, A. R. \& M. A. GorovsKY: Numbers of 5S and tRNA genes in macro- and micronuclei of Tetrahymena pyriformis. Chromosoma 54, 327-337 (1976)

69. LASKEY, R. A. \& I. B. GURDON: The induction of polyoma DNA synthesis by injection into frog egg cytoplasm. Eur, J. Biochem. 37,467-471 (1973)

70. LEICK, V.: Growth rate dependency of protein and nucleic acid composition of Tetrahymena pyriformis and the control of synthesis of ribosomal and transfer RNA. Compt. Rend. Trav. Lab. Carlsberg 36, 113-126 (1967)

71. Lin, S. \& A. RigGs: Lac operator analogues: bromodeoxyuridine substitution in the lac operator affects the rate of dissociation of the lac repressor. Proc. Natl. Acad. Sci. 69, 25742576 (1972)

72. LykKesfeldt, A. E.: Effect of 5-bromodeoxyuridine on Tetrahymena pyriformis grown in low concentrations of tetrahydrofolic acid. Compt. Rend. Trav. Lab. Carlsberg 40, 91 $100(1974)$

73. Lykkesfeldt, A. E. and H. A.AAndersen: The effect of 5-bromodeoxyuriine on DNA replication and cell division in Tetrahymena pyriformis. J. Cell Biol. 62, 316-321 (1974)

74. Lykkesfeldt, A. E. \& H. A. ANdERSEN: Inhibibition of rRNA synthesis following incorporation of 5-bromodeoxyuridine into DNA of Tetrahymena pyriformis. J. Cell Sci. 17, $495-502$ (1975)

75. Lykkesfeldt, A. E. \& H. A. Andersen: Studies on the molecular basis for inhibition of cell proliferation by 5-bromeoxyuridine. In: "Progress in Differentiation Research" MüllerBérat, N. et al., eds., North-Holland Publ. Comp., Amsterdam. pp. 71-76 (1975)

LYKKESFELDT, A. E.: Mechanisms of Action of 5-Bromodeoxyuridine based on Studies with Tetrahymena pyriformis, Carlsberg Res. Commun. 42, 45-66 (1977)

76. LYKKESFELDT, A. E. and H. A. ANDERSEN: Preferential inhibition of rDNA transcription by 5-bromodeoxyuridine. J. Cell Sci. 25, 95-102 (1977)

77. LøVLIE, A.: Growth in mass and respiration rate during the cell cycle of Tetrahymena pyriformis. Compt. Rend. Trav. Lab. Carlsberg 33, 377-413 (1963)

78. Marunouchi, T.\& W. Messer: Replication of a specific terminal chromosome segment in $E$. coli which is required for cell division. J. Mol. Biol. 78,211-228 (1973)

79. McDonald, B.: Quantitative aspects of DNA metabolism in an amicronucleate strain of Tetrahymena. Biol. Bull. 114, 71-94 (1958)

80. Mowat, D., R. E. Pearlmann, \& J. Engberg: DNA synthesis following refeeding of starved Tetrahymena pyriformis. Exptl. Cell Res. 84, 282-286 (1974)

81. Mueller, G. C. \& K. Kajiwara: Early- and late-replicating deoxyribonucleic acid complexes in HeLa nuclei. Biochim. Biophys.Acta 114, 108-115(1966)

82. Murti, K. G. \& D. M. Prescott: Micronuclear ribonuclei acid in Tetrahymena pyriformis. J. Cell Biol. 47, 460-467 (1970)

83. Nakai, G. S., E. Guganig, R. O. Kelly \& R. B. LOFTFIELD: Cytoplasmic DNA in 90-Sr-induced rat chloroleukemia. Rev. Eur. Etud. Clin. Biol. $16,560-563$ (1971)

84. NANNEY, D. L.: Caryonidal inheritance and nuclear differentiation. Amer. Natur. 90, 291 307 (1956)

85. NExø, B. A.: Indholdet af ribo- og 
deoxyribonukleotidtriphosphater i Tetrahymena kulturer. Thesis, University of Copenhagen.

86. Nilsson, J. R.: Suggestive structural evidence for macronuclear "subnuclei" in Tetrahymena pyriformis GL. J. Protozool. 17, 539-548 (1970)

87. Nilsson, J. R.: Physiological and structural studies on Tetrahymena pyriformis GL. Compt. Rend. Trav. Lab. Carlsberg 40,215-355 (1976)

88. Nilsson, J. R. \& E. Zeuthen: Microscopical studies on the macronucleus of heat synchronized Tetrahymena pyriformis GL. Compt. Rend. Trav. Lab. Carlsberg 40, 1-18 (1974)

89. ORIAS, E. \& M. Flacks: Macronuclear genetics of Tetrahymena. I. Random distribution of macronuclear gene copies in Tetrahymena pyriformis, syngen 1. Genetics 79, 187-206 (1975)

90. Pardue, M. L.: Localization of repeated DNA sequences in Xenopus chromosomes. Cold Spring Harbor Symposia on Quantitative Biology, XXXVIII, 475-482 (1973)

91. Plaut, W., D. Nash \& T. Fanning: Ordered replication of DNA in polytene chromosomes of Drosophila melanogaster. J. Mol. Biol. 16, 85-93 (1966)

92. Prescott, D. M.\& K. G. Murti: Chromosome structure in ciliated protozoans. Cold Spring Harbor Symposia on Quantitative Biology, XXXVIII, 609-618 (1973)

93. RAO, P. N. \& R. T. JoHNSON: Mammalian cell fusion: studies on the regulation of DNA synthesis and mitosis. Nature, 225, 159-164 (1970)

94. RaO, P. N. \& R. T. Johnson: Premature chromosome condensation: a mechanism for the elimination of chromosomes in virus-fused cells. J. Cell Sci. 10,495-513 (1972)

95. Rasmussen, L. \& L. ModeweG-Hansen: Cell multiplication in Tetrahymena cultures after addition of particulate material. J. Cell Sci. 12, 275-286 (1973)

96. Rudick, M. J. \& I. L. Cameron: Regulation of DNA synthesis and cell division in starved-refed synchronized Tetrahymena pyrifcrmis HSM. Exptl. Cell Res. 70, 411-416 (1972)

97. Rutter, W. J., R. L. Pictet \& P. W. Morris: Toward molecular mechanisms of developmental processes. Ann. Rev. Biochem. 42, 601-646 (1973)

98. Scherbaum, O. H.: The content and composition of nucleic acids in normal and synchronously dividing mass cultures of Tetrahymena pyriformis. Exptl. Cell Res. 13, 24-30(1957)

99. Scherbaum, O. H., A. L. Louderback \& T. L. JAHN: DNA synthesis, phosphate content and growth in mass and volume in synchronously dividing cells. Exptl. Cell Res. 18, 150-166 (1959)

100. Scherbaum, O. \& E. Zeuthen: Induction of synchronous cell division in mass cultures of Tetrahymena pyriformis. Exptl. Cell Res. 6, 221227 (1954)

101. Schwartz, A., P. R. CoOK \& H. Harris: Correction of a genetic defect in a mammalian cell. Nature, New Biology 230, 5-8 (1971)

102. Shannon, K. P., B. G. Spratt \& R. J. Rowbury: Cell division and the production of cells lacking nuclear bodies in a mutant of Salmonella typhimurium. Molec. Gen. Genetic $118,185-197(1972)$

103. SONNEBORN, T. M.: Tetrahymena pyriformis. Handbook of Genetics. King, R. C., ed., vol. 2, pp. 433-467 (1975)

104. Stubblefield, E.: Mammalian chromosomes in vitro. XIX. Chromosomes of Don-C, a Chinese hamster fibroblast strain with a part of autosome lb translocated to the Y chromosome. J. Natl. Cancer Inst. 37, 799-803 (1966)

105. Tobia, A. M., C. L. Schildkraut \& J. J. Maio: Deoxyribonucleic acid replication in synchronized cultured mammalian cells. I. Time of synthesis of molecules of different average guanine+cytosine content. J. Mol. Biol. 54, 499 . $515(1970)$

106. Todaro, G. J, \& R, J, Huebner: The viral oncogene hypothesis: new evidence. Proc.Natl. Acad.Sci. 69, 1009-1015 (1972)

107. Tonnesen, T., J. Engberg \& V. Leick: Studies on the amounts and location of the tRNA and 5S RNA cistrons in Tetrahymena pyriformis by DNA:RNA hybridization. J. Protozool. 21, (suppl) 462 (1974)

108. Tønnesen, T., J. Engberg \& V. Leick: Studies on the amount and location of the IRNA and SS rRNA genes in Tetrahymena pyriformis GL. Eur. J. Biochem. in press.

109. Tønnesen, T. \& H. A. Andersen: Timing of $5 \mathrm{~S}$ RNA- and tRNA gene replication in Tetrahymena pyriformis. Exptl. Cell Res. 106, 408-412 (1977)

110. Villadsen, I. S.\& E. Zeuthen: Synchronization of DNA synthesis in Tetrahymena populations by temporal limitation of access to thymine compounds. Exptl. Cell Res. 61, 302-310 (1970)

111. Vorob'ev, V. I., S. N. Borchsenius, N. A. Belozerskaya, N. A. Merkulova \& I. S. IRLINA: DNA replication in macronuclei of Tetrahymena pyriformis GL. Exptl.Cell Res. 93,253-260(1975)

112. Woodard, I., M. Gorovsky \& E. Kaneshiro: Macronuclear subnuclei in Tetrahymena. J. Cell Biol. 39, 182a. (1968) 
113. Woodard, I., E. Kaneshiro \& M. A. GoRovsky: Cytochemical studies on the problem of macronuclear subnuclei in Tetrahymena. Genetics 70, 251-260 (1972)

114. YAO, M.-C. \& M. A. GorovsKY: Comparison of the sequence of macro- and micronuclear DNA of Tetrahymena pyriformis. Chromosoma 48, 118 (1974)

115. YAO, M.-C., A. R. KıMmel \& M. A. GoRovsKY: A small number of cistrons for ribosomal RNA in the germinal nucleus of an eukaryote, Tetrahymena pyriformis. Proc. Natl. Acad. Sci. 71, 3082-3086 (1974)

116. Zeuthen, E.: Introduction to "Synchrony in Cell Division and Growth", E. Zeuthen, ed., Interscience Publishers, New York-London, pp. 1$8(1964)$

117. Zeuthen, E.: Thymine starvation by inhibition of uptake and synthesis of thymine-compounds in Tetrahymena. Exptl. Cell Res. 50, 37-46 (1968)

118. ZEUTHEN, E.: Independent synchronization of DNA synthesis and of cell division in same culture of Tetrahymena cells. Exptl. Cell Res. 61,311-325(1970)

119. ZEUTHEN, E.: Synchronization of the
Tetrahymena cell cycle. In: "Advances in Cell Biology", Prescott, D. M., L. Goldstein \& E. McConkey, eds., Appleton-Century-Crofts, New York, Vol.2, pp. 111-152 (1971)

120. Zeuthen, E.: Synchrony in Tetrahymena by heat shocks spaced a normal cell generation apart. Exptl. Cell Res. 68, 49-60(1971)

121. ZeUthen, E.: A cellular model for repetitive and free-running synchrony in Tetrahymena and Schizosaccharomyces. In: "Cell Cycle Controls", Padilla, G. M., I. L. Cameron \& A. Zimmerman, eds., Academic Press, New York, pp. 1-30 (1974)

122. Zeuthen, E.: Studies on the cell cycle. University Press, Clumbus, Ohio (1976)

123. Zeuthen, E. \& O. Scherbaum: Synchronous divisions in mass cultures of the ciliate protozoan Tetrahymena pyriformis, as induced by temperature changes. In: "Proceedings of the 7th Colston Symp., Recent Developments in Cell Physiology", J. A. Kitching, ed., Butterworth, London, pp. 141-156 (1954)

124. Zeuthen, E. \& L. Rasmussen: Synchronized cell division in protozoa. In: "Research in Protozoology", T. T. Chen, ed., Pergamon Press, New York-Oxford, vol, 4, pp. 9-145 (1972) 